\title{
Sustainable Health Insurance
}

\author{
Gilbert Berdine MD
}

$\boldsymbol{P}_{\text {art } 1} 1$ of this series on sustainable health care examined the basics of sustainability. ${ }^{1}$ In this segment, the role of insurance is examined. The characteristics of sustainable or actuarially sound insurance are presented. These characteristics are contrasted with what is improperly called "insurance" today.

\section{BASICS OF TRADITIONAL INSURANCE}

The proper use of insurance is to pool risk of loss among many people such that catastrophic events do not bankrupt an individual. Insurance predates money. ${ }^{2}$ Community granaries were a means of insuring against famine. Some societies, including the Amish, had arrangements that insured housing. If a house was destroyed by a natural disaster, the neighbors were committed to help rebuild the house. ${ }^{3}$ The earliest insurance in monetary economies involved insurance of trade cargo. ${ }^{3}$ The ancient Chinese pooled the risk of losing trade cargo to natural disaster by distributing cargo among many ships as early as $3000 \mathrm{BC} .^{3} \mathrm{~A}$ merchant who took out a loan to purchase cargo would pay an additional sum for insurance that would cancel the loan in the event the cargo was lost. Loan forgiveness due to natural disaster as well as the practices of using trade ships or trade cargo as collateral for insurance were established in the ancient Babylonia Code of Hammurabi around $1754 \mathrm{BC}^{3}$ Insurers had incentives to promote prudent practices that would minimize the risk of loss. Insurers might not agree to insure someone who would not adopt these prudent practices.

Financially sound insurance must calculate a premium based on the actual risk. Averaged over many insured, the payments from the insured to the insurer must exceed the amount paid out by the insurer for

Corresponding author: Gilbert Berdine

Contact Information: Gilbert.berdine@ttuhsc.edu DOI: $10.12746 /$ swrccc.v6i25.488 claims made by the insured. Some of the excess pays for the administrative costs of the insurance business such as record keeping. Proper insurance requires that funds insuring against catastrophe must not be used for purposes other than the payment of claims as the funds must be immediately available to pay legitimate claims. In other words, these funds must be available on demand rather than invested in long term ventures. The insurer expects to earn money by offering the insurance. The risk assessment must be as accurate as possible to enable the insurer to determine the lowest possible price. Furthermore, if the insurer can earn more by funding some other economic activity, the insurer would abandon the insurance business in favor of more profitable enterprise.

Insurance enables people with fewer assets to get involved in business. Let's say, hypothetically, the historic risk to cargo loss is $1 \%$ of ships per year. A wealthy trader with 200 ships would not purchase insurance, but would accept the expected loss of 2 ships per year as one of the costs of doing business. There would be no point to buying insurance as the insurance premium would exceed the expected annual loss of 2 ships per year. A modest trader might not have the luxury of treating catastrophic loss as an ordinary business expense funded from cash flow. Let's further say, hypothetically, the trader can buy a cargo for $\$ 1000$ and can sell the cargo in a distant port for $\$ 2000$. The trader's capital is only $\$ 500$, so the trader must take out a loan to purchase the cargo. Let's further say, hypothetically, the lender will lend the $\$ 1000$ and expects $1 \%$ interest on repayment. If the ship is lost, the trader would be bankrupted and unable to repay the loan. If an insurer will insure the cargo for a premium of $2 \%$ or $\$ 20$, the trader can borrow the money, pay the interest on the loan, pay the insurance premium, and realize a profit of $\$ 970$ after selling the cargo. If the cargo is lost, the trader is still able to repay the loan with the insurance payment and afford the insurance premium and the loan interest from his existing capital. Note that the trader is better off if the cargo is not lost, so there is no moral hazard 
introduced by the insurance; there is no incentive for the trader to lose the cargo on purpose to collect a payment. The insurer makes a profit on his insurance provided that the insurance premium exceeds the average expected loss and he insures a large enough number of people such that a single loss does not wipe out all the successful voyages.

The above trading example makes the principles of actuarially sound insurance clear. The insurer must charge a sufficient premium to pay for the expected claims. The insurer will not insure events after they have happened. Nobody would be permitted to purchase cargo insurance after the ship has sunk in a storm. If a captain gains a reputation of losing ships, nobody will insure his voyages. Everyone involved has an incentive to reduce the number of adverse events. Neither the insurer nor the insured are better off if an adverse event triggers a claim. The insurance permits entrepreneurs of modest means to engage in profitable activities that have large capital requirements, thus increasing competition.

\section{DifFERENCES BETWEEN HEALTH "INSURANCE" AND TRADITIONAL INSURANCE}

Now we can examine so-called health insurance and see how it differs from the above description of actuarially sound cargo insurance. In the cargo insurance example, the trigger for a claim - loss of cargo - is well defined. The amount of the claim is, likewise, well defined. So-called health insurance is not well defined. Is the insurance company required to pay for medication prescribed by a physician? Can the insurance company deny the claim as being medically unnecessary? For example, is a scooter medically necessary or a nice convenience? Can the insurance company substitute another remedy for the prescribed remedy? For example, can the insurance company require that albuterol be substituted for Xopenex? Are some remedies excluded due to high cost? For example, is the insurance company required to pay for Esbriet to treat pulmonary fibrosis? Is the insurance company responsible for remedies that did not exist when the contract was made? The public sees the insurance company as a deep pocket that should bear any cost, while the insurance companies demand subsidies and rate increases. Rather than the insured negotiating with the insurer to obtain an insurance contract that is mutually beneficial, both the insured and insurers appeal to politicians for government intervention to make the contracts favorable to one party and required by the other party.

Moral hazard is a key problem with so-called health insurance. In the cargo insurance example, nobody had an incentive to lose the cargo, so the motives of both the insured and the insurer remain honorable. The situation with so-called health insurance is quite different. Providers of fee for service health care have an incentive to file excessive claims, run more tests, schedule more visits, and recommend more treatments than the patients would accept if payment were out of pocket. Much to the chagrin of insurers, the historic metric for health care has been improved outcome with complete disregard to cost. Providers of health care have an incentive to charge excessive fees that are not paid by their patients. The providers have an incentive to reclassify nice conveniences (scooters) as medical necessities. The insurers have an incentive to deny claims as medically unnecessary. The insurers want to reclassify medical necessities (CPAP machines) as nice conveniences. The so-called health insurance has transformed the mutually beneficial relationship of traditional insurance into an adversarial relationship where the providers, patients, and insurers are no longer seeking mutual benefit.

\section{MORAL HAZARD OF $3^{R D}$ PARTY PAYERS}

Another principle of sound insurance is that beneficiaries pay the insurance premiums. When the person who benefits from a claim is different from the person paying the insurance premium, we introduce another type of moral hazard in which the insured want every treatment irrespective of cost and the insurer wants to deny every claim irrespective of benefit. There is no compelling reason for employers to provide health insurance for employees other than for specific risks related to employment. While a construction company might very well provide employees 
insurance against injuries incurred on the job, there would be no compelling reason for the employer to insure against illnesses unrelated to employment absent government incentives to do so.

If there is no compelling reason to attach health insurance to employment, why is this practice the norm in the U.S.? The provision of health insurance by employers is an accident of government wage controls during World War II and tax policy. Conscription during World War II led to worker shortages in many factories. Wage and price controls unwisely put in place to deal with shortages of many goods and services made it impossible for employers to attract workers with higher wages. Employers were permitted to offer benefits, including health insurance, as incentives to attract new workers.

Why has employer provided health insurance persisted after the wartime wage and price controls were eliminated? Tax policy gives a deduction for business expenses of employer provided health insurance, but does not give a tax deduction to health insurance purchased by employees. This tax deduction makes health insurance cheaper for the employer to purchase than the employee. The health risks of employed people are not identical to the health risks of the general population. This was particularly true post World War II when blue collar factory jobs were more prevalent than today. Individuals capable of working an assembly line for an 8-hour shift are, on average, in better health than the general population which includes many who cannot endure the physical demands of employment. Furthermore, employees paid an hourly wage have a disincentive against taking time off for being ill. Groups of people are more likely to fit the statistical norms. Individuals may be outliers with pre-existing conditions known to them but not to anyone else. Employment is an indicator of lower actuarial risk for health claims. These factors, and others, make the actuarial risk of employees lower than individuals who are not employed. Employer provided insurance was, for good reasons, cheaper to purchase than individual insurance policies. Unfortunately, this practice of health insurance as a benefit of employment has helped to create a sense that individuals should not be responsible for providing their own health insurance. Combined with some of the effects of Medicare and Medicaid, the population has come to view health insurance as an entitlement to subsidized health care rather than a means to pool outlier risks.

When people provide their own health insurance through individual policies, there are no problems with portability. Furthermore, it becomes possible to purchase policies that cover longer time frames, which are impractical for insuring employees. Employment based health insurance can lead to adversarial employer-employee relationships; an employer might be very happy with the work performed by an employee, but can find a replacement employee who is much cheaper to insure. Labor laws have changed post World War II making discrimination against the disabled illegal, but there are ways to legally circumvent the restrictions. U.S. labor law cannot prevent an employer from moving a factory to another country. In some cases, it is the cost of insuring workers rather than low wages that move jobs overseas. This problem can impact older and more experienced employees. A layoff for health insurance cost reasons compounds the loss of health insurance with the loss of income from employment.

\section{Pre-existing conditions}

The example of cargo insurance makes it clear why pre-existing conditions are not insurable. Nobody would expect to purchase cargo insurance AFTER a ship has been sunk by a storm. Nobody considers it a right to purchase fire insurance AFTER a house has burned down. A patient with a pre-existing condition cannot share risk with other people, because there is no uncertainty that the patient MIGHT develop a condition. Grouping people who have known costs of care together with other people who have uncertain risks of incurring costs of care is a subsidy from the people without the pre-existing condition to the people with the pre-existing condition. Given an option to decline participation in such a scheme, patients without pre-existing conditions may find it more desirable to go without insurance and take their chances. This situation has been made clear by the Individual 
Mandate portion of ACA which has recently been eliminated. ${ }^{4}$

\section{Catastrophic loss vs. maintenance}

The example of cargo insurance clarifies the issue of which items should be covered by insurance. Loss of the cargo during transport is an insurable event. One does not insure the upkeep of the cargo. For example, a cargo of livestock would have to be fed and watered during the voyage. One does not purchase insurance for the upkeep, because this is a certain cost, so there is no risk to share with other merchants. If one cannot afford the upkeep of the cargo during the voyage, then one should not be in the business of buying and selling cargo. Similarly, while one can insure against being hit by a truck, insuring the cost of an annual examination would be silly. Being hit by a truck is rare, catastrophic, and uncertain, so this situation is ideal for insurance. In contrast, the costs of the annual examination are known and certain. There is no risk to share, so the annual examination should not be covered by insurance. A less obvious example is screening for colon cancer by colonoscopy at age 50 . Reaching the age of 50 is not an insurable event. Even if screening colonoscopies lead to improved outcomes, and even if screening colonoscopies reduce average health care expenditures, the screening colonoscopy should not be covered by insurance. Each person must save while they are young to be able to purchase the screening colonoscopy at age 50 .

Insuring maintenance leads to problems similar to "splitting the check" at a fancy restaurant. If people know that the check will be split before ordering, they are inclined to order more expensive items than they otherwise would, so the final bill is higher than it would be if everyone paid for their own meal. Invariably, some people feel that they have been taken advantage of which leads to resentments by those who order less expensive meals against those who had more expensive tastes.

Some events are more difficult to classify. While the surgery and acute care for trauma are clearly insurable, what about the pain medications and physical therapy required after the hospital stay? What about disability payments? As coverage goes beyond the short term and more easily estimated items, extending to things that are longer term, the possibility of greater risk variation grows.

\section{Coverage for old AGE AND CHRONIC ILLNESS}

The above discussion is a perfect segue into the biggest problem for health insurance: coverage for chronic illness and old age. As we age, the likelihood of developing health problems and requiring health care increase. An acute myocardial infarction is much more likely at age 60 than at age 30 . We will all eventually die of something. Every person will face end of life with absolute certainty, which cannot be insured.

What about life insurance? There is a robust market for actuarially sound life insurance, but life insurance is different from health insurance in key features. Term life insurance pays a fixed sum - agreed upon by both the insurer and the insured - if the insured dies within a certain time. The policy may be renewed, but the premiums increase with age. Obviously, the premiums scale to the payout amount.

Health insurance, in contrast, is open ended with respect to cost. The payout for a death covered by life insurance is explicitly defined in the contract, as was the case for the cargo insurance example. Like cargo insurance, the trigger condition for the payout event is also well defined for life insurance. The payout for health insurance is less clear. Consider acute myocardial infarction as an example. Conservative medical management is much less expensive than interventions. This leads to disagreements among the providers of health care, the insured, and the insurers about what treatment is "needed." The interventional cardiologist frequently recommends the more expensive therapy. The insurance company might not agree about necessity. A salesman does not question the need for a toaster purchase. The need is met when the buyer agrees to pay the purchase price. "Need" for health care is poorly defined because the receiver of the benefit of care - the patient - is not the payer for the benefit. 


\section{HEALTH INSURANCE STRUCTURED LIKE TERM LIFE INSURANCE}

Term life insurance gives us some insights on the types of health insurance policies that would be actuarially sound. It would be actuarially sound to offer a term policy against the occurrence of an acute myocardial infarction within a specific time frame with a pre-determined payout. The insurance premium for such a policy would be greater for an older person compared to a younger person. A person with a previous myocardial infarction would have a greater risk and therefore a higher premium. The premium would scale to the stipulated payout. A policy that covered the cost of conservative medical management would have a lower premium than a policy that covered the cost of coronary stenting or coronary artery bypass graft.

The comparison with term life insurance explains why it is necessary to separate health maintenance from insurable conditions. Term life insurance insures against death which is, under most circumstances, not voluntarily chosen. Most term life insurance policies explicitly deny claims for suicide because covering death by suicide would make life insurance actuarially unsound. Including health maintenance in health insurance encourages overuse of the insured item. It would be silly, for example, to offer an insurance policy against being hungry or sleepy. Most people can avoid these conditions, but might not if there were a reward.

Health insurance works best when the trigger conditions for payout are well defined, are objective in nature, and are not determined by either the insurer or the insured. Life insurance and cargo insurance meet these criteria. Death is objective: a death is determined by a disinterested party to the insurance policy, and the payout for death was explicitly stated in the insurance contract. Health insurance can cover a myocardial infarction, but it should not cover a headache. The existence of the myocardial infarction can be defined by objective test results, but the symptom of headache is subjective and determined only by the insured. Headache should be treated as health maintenance and be paid for by each individual. The payout for a health insurance adverse event should either be stipulated explicitly in the contract, or the remedy should be determined by a disinterested party other than the provider, the insurer or the insured. Stipulating the payout explicitly in advance is likely to be the least expensive means of administering the policy.

\section{COST SHARING OF OUTLIER EVENTS VS. COST SHARING OF ROUTINE COST OF LIVING (AND DYING)}

Insurance cannot make the cost of events go away; it can only distribute the risks of claims over many people. Common events expected to occur on a regular basis should not be insured. There is little value to having insurance cover the cost of an annual checkup. The annual checkup should be paid by each individual at the time of the checkup. As the catastrophic event becomes less likely to occur to any given individual, the event becomes more suitable for insurance coverage. Returning to the cargo insurance example, if $1 \%$ of cargoes are lost to storms, then an enterprise trading 200 cargoes per year can expect to lose 2 cargoes each year; this is a cost of business rather than an insurable event. Large enterprises that self-insure are treating the cost of health care as a business expense that is payable regularly over time out of normal cash flow. Insurance offers individuals and small enterprises the ability to share the expenses of adverse events with a large enough group such that the cost of paying for adverse events can be paid out of pooled funds.

Government health care programs like Medicare, Medicaid and the Affordable Care Act (ACA) are labeled as health insurance, but they are subsidies rather than insurance. Medicaid is the easiest to understand as a subsidy. Medicaid requires the health care of its beneficiaries to be subsidized by taxpayers. Medicare is billed as a program where people pay in when they are young and receive health care benefits when they are old or disabled. There is an illusion of a Trust Fund that holds the payments for future use, but the Trust Fund is an accounting gimmick. The reality of Medicare is that the payments of beneficiaries are a very small portion of the total expenses. The differences are made 
up by payments of young people who do not qualify for benefits at this time as well as a sizeable contribution from General Tax Revenue. Medicare is largely a subsidy from the tax paying public to the Medicare beneficiaries. ACA is a subsidy from the healthy to the ill. ACA makes stratification of risk mostly illegal, so everyone is required to join a single risk pool. This is a great deal for people with known conditions and certain expenses, such as dialysis patients, but it is a very poor deal for healthy people who may make no claims for health care. ACA forced individuals with low risks to pay higher insurance premiums than necessary for their risk in order to cover the high known costs of people with pre-existing conditions. The original ACA had an Individual Mandate that required low risk people to participate. Now that the Individual Mandate has been eliminated, the future of ACA is very uncertain as low risk people leave the risk pool making the risks increase over time. Medicare, Medicaid and ACA are all subsidies that separate the person receiving the benefit from the person paying for the benefit which predictably leads to overutilization of health care. The beneficiary only cares about efficacy and is unconcerned about cost.

How should society pay for the care of the elderly? Since end of life cannot be insured, insurance is not the answer. The first line of defense should be savings accrued earlier in life while the person was healthy and able to work. Just as a Rolls-Royce costs more than a Chevrolet, some health care options cost more than other health care options. What about situations in which the elderly face expenses they cannot afford? The burden of these cases should fall on those who benefit from the care. The obvious first choice is the person receiving care. The next in line would be family members who have the most to gain by the medical care of their loved one. It should be obvious that the benefits of health care provided to an elderly person are more valuable to a family member than to a complete stranger. The person receiving the most value from health care benefits should be most responsible for the costs. Next in line would be friends and neighbors. Charity, in the proper sense, is a special type of system in which the benefit of treatment and cost of treatment are joined in those who freely donate to the charity. This attachment of the burden of cost to the benefit of treatment avoids moral hazard. Our system turns the hierarchy of benefit upside down and pretends that we have zero responsibility for our own health care and $100 \%$ responsibility for the health care of complete strangers. These issues will be discussed in greater detail in Part 3 which covers the role of charity in a sustainable health care system. The important differences between charity care and socialized care will be illustrated.

Keywords: insurance, health care, risk, catastrophic events, routine care

Article citation: Berdine G. Sustainable Health Insurance. The Southwest Respiratory and Critical Care Chronicles 2018;6(25):63-68

From: Department of Internal Medicine at Texas Tech University Health Sciences Center in Lubbock, Texas

Submitted: $5 / 16 / 2018$

Accepted: $7 / 3 / 2018$

Reviewers: Brent D. Magers FACHE, FHFMA, CMPE; Brent King MBA

Conflicts of interest: None

\section{REFERENCES}

1. Berdine G. Affordable health care: What it means and how do we fix our current unaffordable system. The Southwest Respiratory and Critical Care Chronicles 2017;5(21):36-41.

2. A Brief History of Insurance Throughout the Ages. https:// www.columbusdirect.com/content/insurance-history/. Accessed 5/10/2018

3. History of insurance. https://thismatter.com/money/insurance/ insurance-history.htm. Accessed 5/10/208.

4. Soffen K. How the Senate bill could send the health insurance market into a death spiral. 6/23/2017. https://www. washingtonpost.com/news/wonk/wp/2017/06/23/republicanssay-the-health-insurance-market-is-in-a-death-spiral-their-billcould-make-it-really-happen/?noredirect=on\&utm_term $=$. d1f4d53cb2d8. Accessed 5/10/2018. 